\title{
IDEAS COMPETITION FOR THE DESIGN AND CALCULATION OF A FOOTBRIDGE IN TALAMANCA DE JARAMA (MADRID)
}

\author{
A.B. Berrocal, S. Blanco, J. Bernabéu \\ Universidad Politécnica de Madrid (SPAIN)
}

\begin{abstract}
The proposed experience consists in the organization of an idea competition for the design and calculation of a footbridge on a stream of the Madrid municipality of Talamanca de Jarama. This project is designed within the framework of educational innovation projects of the Universidad Politécnica de Madrid carried out in the School of Civil Engineers. The project has been structured in several phases, all based on experiential learning and collaborative work.

There are five teams for the competitions. Each one formed by a student of the last year of the Master of Civil Engineering, who has to make his/her academic final project, and a teacher of the School of Civil Engineering of Madrid, who would do the role of tutor.

The first months are dedicated to collaborative work of all students through workshops and visits to the location of the footbridge. Later, the students work with their tutor generating the idea they will present to the competition.

This experience allows the student to have contact with the real professional activity, to talk with social agents and to obtain data from the land by measuring flows or distances. On the other hand, municipality benefits with semi-professional projects without costs.
\end{abstract}

Some students present their project using virtual reality thanks to a workshop dedicated to this issue.

In order to select the best project, a court is created. Specialists in different areas of the projects take part of this court. Also, a percentage of the final poll depend of popular criteria in two ways: by the election of the student of the School, and by the election of the citizens of Talamanca. This part of the project is based on gaming, an educational innovate technique based in the concep of game (competitiveness, motivation, rewards). One hundred thirty five people have participated in the voting.

In summary, this project reproduces the phases of a real project ending with an idea competition but also incorporates a collaborative work that enriches and motivates the student.

Keywords: footbridge, ideas competition, experiental learning, virtual reality.

\section{INTRODUCTION}

Technological developments are transforming the conception of Higher Education and how students pursue an advanced degree. In this moment, the diversification of the student population requires the individualization of learning, a more flexible approach that challenges traditional paradigms and a greater focus on the pedagogies that provide support to students.

Moreover, these changes entail a series of transformations in the teaching methodology, allowing the student to become more responsible for their own learning process. This is achieved by engaging with cogitation processes, interacting with their environment and developing, among other skills, autonomy, critical thinking, collaborative attitudes, professional skills and self-assessment skills [1].

Educational innovation projects aim to offer the students new methodologies so they can work in and outside the classroom, being an active subject and building their own learning. In this process, ICTs have become a powerful tool to help facilitate pedagogical innovation [2].

Furthermore, on account of the social responsibility involved in the task of teaching and learning, it is necessary to renew the individual commitment of teachers and students and, in this way, look for new ways to overcome the challenges the university is currently facing [3]. In Einstein's words, "we can not solve problems using the same kind of thinking we use when we create them."

Therefore, our students will have to give effective answers to the challenges and problems that will arise in their uncertain future, and from the university we must prepare them to be able to deal with these challenges. Collectively sharing experiences and reflections is one of the best ways for 
continuing education [4], fostering the students' capacity to apprehend reality, allowing them to think and behave flexibly with what we know to solve problems, to create products and interact with the world around us [5] [6].

The presented project tries to develop these abilities through the experiential learning of the students, the collaborative work and the use of the ICTs by participating in an ideas competition intended to generate designs of pedestrian bridges.

\section{METHODOLOGY}

The project consisted in the organization of an ideas competition for the design and calculation of a pedestrian bridge over a river in Talamanca de Jarama, a municipality of Madrid. Participation was offered to the students in the last year of the Master Degree of Ingeniero de Caminos, Canales y Puertos, (School of Ingenieros de Caminos, Canales y Puertos, in the remaining of the document named as ETSICCP). Four teams were formed, each one composed by a student, being this activity part of her/his master's degree final project, and a teacher who also played the role of advisor. Subsequently, a graduate student was also incorporated to the project, tutored also by his advisor.

Students have associated, therefore, their final degree project to this experience that replicates an ideas competition promoted by a City Council. An existing agreement between the ETSICCP and the Hon. City Council of Talamanca de Jarama for the realization of final degree projects in the municipality was used. The proposal that is here presented connects, therefore, with the idea of "learning by doing", facilitating the student an experiential learning, in this case by participating in an actual ideas competition.

In a first phase of the project the student advisors, being specialists in each of the essential subjects related with the design and calculation of a footbridge, have been responsible for mentoring the students in workshops or field visits that have been carried out jointly. These activities were essentially practical and have usually required the collaboration of all students to solve the problems that arose. In particular, seven workshops have been carried out, the first of them at the location of the footbridge in Talamanca de Jarama and the remaining in the facilities of the ETSICCP.

In the first workshop, the environmental conditions of the location where the footbridge is to be placed where analyzed. The aim of this activity was to get a proper knowledge of all the previous aspects the design of a footbridge entails. Urban, environmental, hydraulic and aesthetic factors were assessed by the students. Simultaneously, a practical introduction to the handling of drones in photogrammetry took place while the realization of a digital survey of the area was performed.

The second seminar aimed to work on the same objectives as the first, the foregoing analysis of the data a footbridge design needs, but in this case related with regulations, plans, technical instructions, etc., which were discussed and worked on together. At the end of the workshop, the students were provided with a technical bibliography about footbridges, which had to be studied outside the classroom once the workshop finished.

After the second seminar, while the students were immersed in the generation and assessment of different alternatives for their footbridges, the third workshop was organized, based on creative design guidelines. The objective of this session was to familiarize the student with the process of creating, generating solutions from scratch and judge them critically. They were invited to make sketches and to use basic cartography to fit their solution in the three dimensional space.

The next workshop, consisting on the post-processing of the drone images, was done immediately afterwards. In this activity it was obtained the digital topography of the area of Talamanca de Jarama where the footbridge is intended to be placed. At the end of the workshop, each of the students got a digital model of the terrain where they could define their project by using a CAD program.

Later on, once the students had chosen a technical solution for their footbridge, two workshops related to the structural analysis were performed. The five students participating in this experience have developed their own design, providing different solutions to the same problem, regarding the definition of the structural type, the location along the river and the aesthetical aspects of the design.

The last two workshops consisted of an introduction to 3D modeling using the students' proposed solutions, and the generation of a model in augmented reality, or computed-mediated reality, by superposing a virtual reality over a physical object using the camera of a smartphone. This last milestone was only reached by one student, helped by his advisor. The dedication and the level of 
knowledge in programming needed made impossible for the other students to achieve this objective, but the experience provided a lot of information about the difficulty that it entailed for a master degree student, regarding future educational innovation initiatives.

All the students have presented their project in a standardized document, adapted to the curricula of the Master's Degree in Civil Engineering and to the Degree in Civil and Territorial Engineering, both degrees at the ETSICCP. In addition, they have prepared a panel sized A1 where they gather and synthesize the fundamental factors of their proposal. On the other hand, teachers have made a video that shows the solutions of the five participants in the project.

All the proposed solutions were evaluated in the ideas competition that was held at the end of October 2017. The competition was publicized in the ETSICCP and in the municipality of Talamanca de Jarama through appropriate digital and physical means. Likewise, the panels were displayed in one of the halls of the ETSICCP along with the publicly screening of a video and the same was done in a public access room in the municipality of Talamanca de Jarama. The jury consisted of several professors of the ETSICCP and the best student of the previous promotion, as well as the councilor of Urbanism of the Hon. City Council of Talamanca de Jarama. In addition, a percentage of the final rating of the proposals was defined by the popular vote of the citizens of the municipality and the community of the ETSICCP through an online survey. This survey could be accessed through the scanning of a QR code, inserted in the publicity of the competition and in the foot of the panels of each proposal. The prize of the contest consisted of a mention and a small monetary reward.

Throughout the project, the evidence of achievement of each student has been assessed through a system of rubrics. In particular, the understanding of design constraints, the acquisition of knowledge for the calculation of structures, the creativity during the generation of alternatives and the definition of the final solution have been measured.

\section{RESULTS}

Each student, tutored by a teacher, has developed a proprietary solution for the footbridge.

Thus, 5 different structural solutions have been obtained:

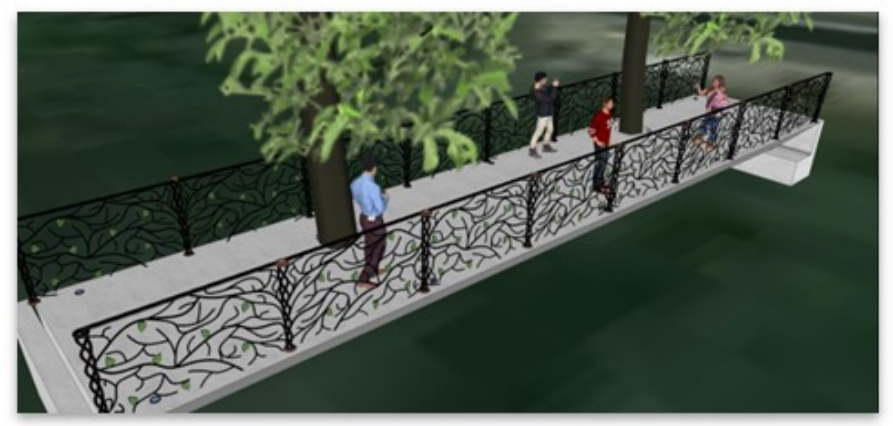

Figure 1. Continuous slab of reinforced concrete, on which two holes have been made for the passage of the trunks of the river trees.

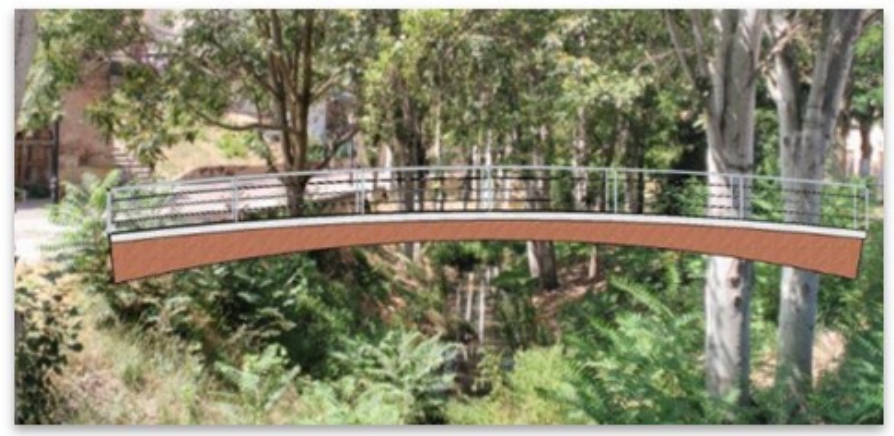

Figure 2. Mixed arch. White concrete board over corten steel arch. 


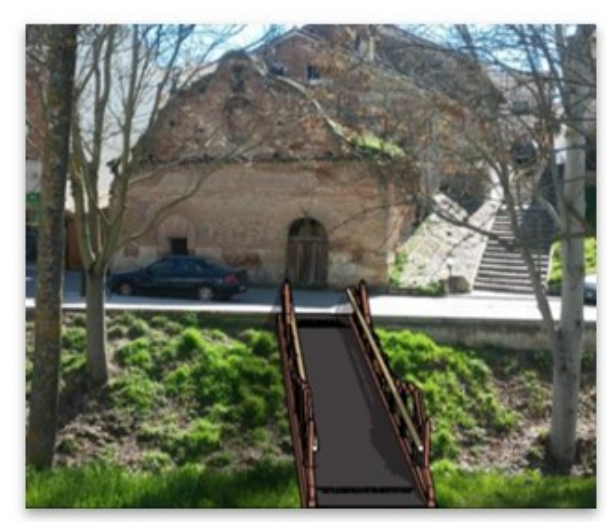

Figure 3. Gangway of braced beams

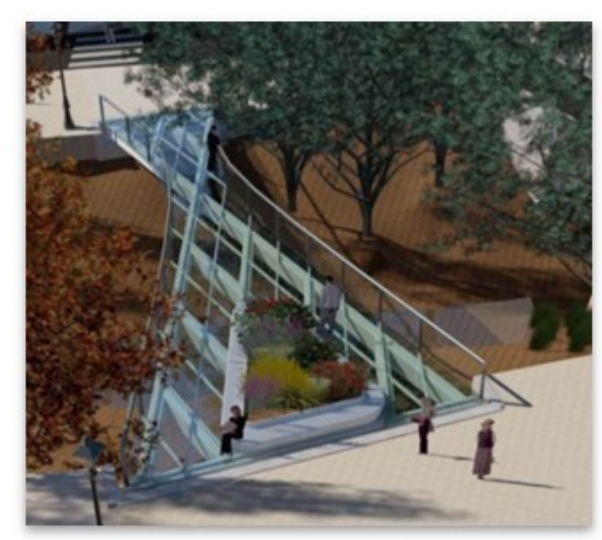

Figure 4. Metal latticework on which a glass pavement rests

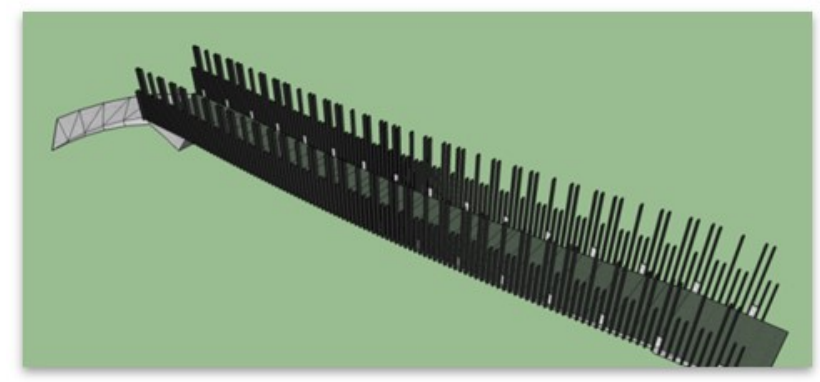

Figure 5. Stressed ribbon footbrigde

It is interesting to see how, faced with the same conditions of departure and the same workshops, each student has developed their creativity in their own solution. All the students have presented a constructive project consisting of all the necessary technical documentation for an eventual construction of the catwalk. In addition, they have made a panel in A1 format in which their Project is summarized. Finally, they were given the option to represent their catwalk in augmented reality. This option was only developed by a student, achieving very satisfactory results.

The evaluation of the proposals was very different according to the type of court. Thus, the expert court, made up of 6 professors from the University and 1 Councilor, positively assessed the most complex and innovative option from the structural point of view, that is, the tesa band. However, this solution, visually very modest, was not highlighted by the popular vote of residents of Talamanca (47 votes), nor by the students of the school (81 votes), who valued the most transgressive option, the slab of Perforated concrete to allow the passage of trees. Given that the weight of these votes was $40 \%$ for the expert court, $30 \%$ for the vote in the school and $30 \%$ for the citizen vote, the final result benefited the option of the perforated concrete slab (figure 6). 


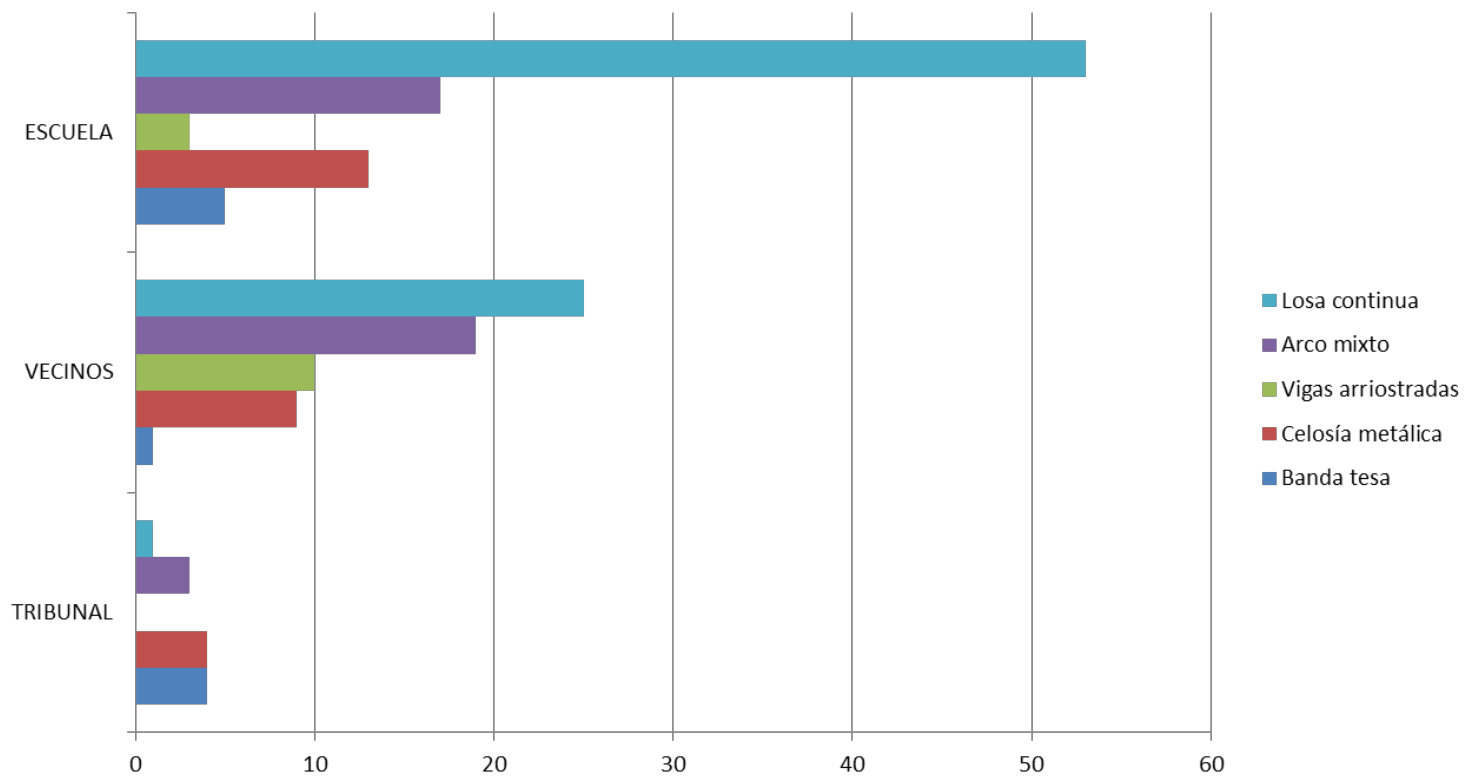

Figure 6. Voting results according to the origin of the vote and the type of structure

Finally, a survey was conducted among the participating students to check the degree of satisfaction with the Project and possible improvements in future projects. Below is a summary table of the main results (Table 1 and Figures 7 to 10). These results show a very high global evaluation of the Project. In phases, the students highlighted the workshop in which the work area was visited and the calculation of structures and graphic representation of the solution. On the other hand, they value highly the degree of previous competence in the subjects to be developed during the Project, but they recognize that they have experienced certain difficulties in some tasks, such as the calculation of the structure.

Table 1. Results of the survey to the participating students

\begin{tabular}{l|c}
\hline \hline Valuation of project phases & {$[\mathbf{0 , 5 ]}$} \\
\hline Phase 1. Understanding the place & $\mathbf{3 , 3}$ \\
\hline Valuation of the Workshop: field work & 4,8 \\
\hline Difficulty for understanding physical and territorial constraints & 2,0 \\
\hline valuation of previous competences & 3,2 \\
\hline Phase 2 \& 3. knowledge of structural shapes and types and design elaboration & $\mathbf{2 , 9}$ \\
\hline Valuation of the Workshops: design and shapes & 3,0 \\
\hline Difficulties in these areas & 2,9 \\
\hline valuation of previous competences & 2,8 \\
\hline Phase 4. Calculation of the structure & $\mathbf{3 , 3}$ \\
\hline Valuation of the Workshop: structural calculations & 3,6 \\
\hline Difficulties in this area & 3,2 \\
\hline Valuation of previous competences & 3,2 \\
\hline Phase 5. Rendering of the proposal & $\mathbf{3 , 0}$ \\
\hline Valuation of the Workshops: rendering & 3,8 \\
\hline Difficulties in this area & 3,0 \\
\hline Valuation of previous competences & 2,4 \\
\hline Gobal evaluation of the project & $\mathbf{4 , 2}$ \\
\hline
\end{tabular}


PHASE 1. UNDERSTANDING THE PLACE

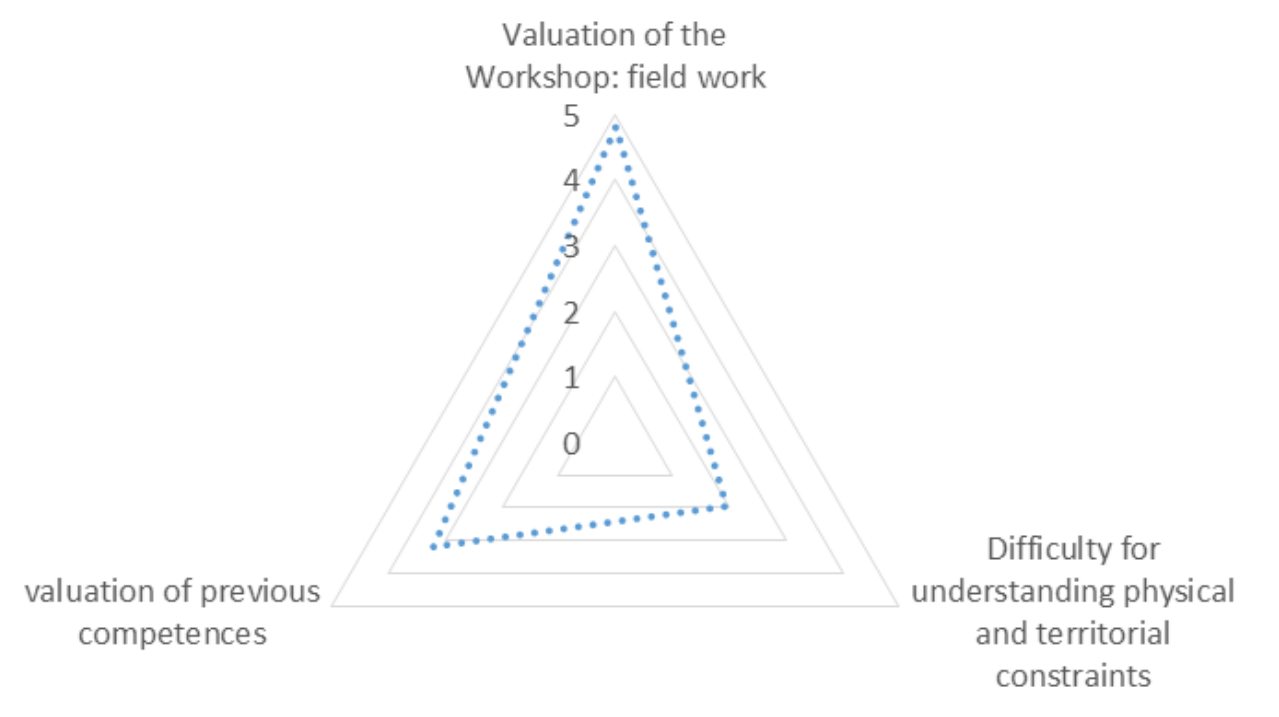

Figure 7. Valuation of the phase 1

PHASE 2 \& 3. KNOWLEDGE OF STRUCTURAL SHAPES AND TYPES AND DESIGN ELABORATION

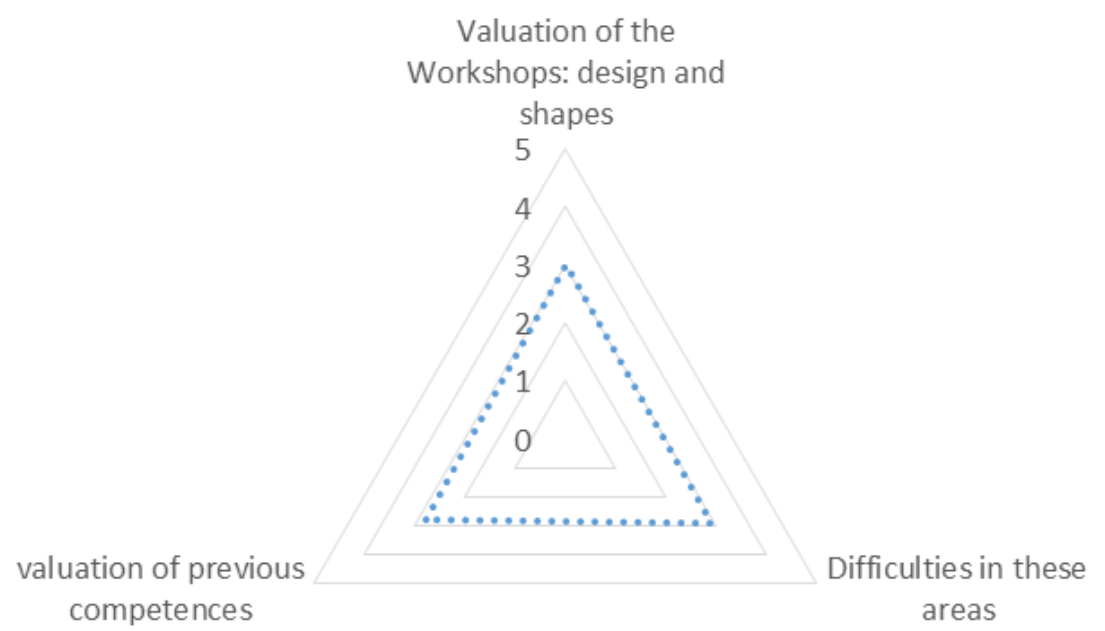

Figure 8. Valuation of the phases $2 \& 3$ 


\section{PHASE 4. CALCULATION OF THE STRUCTURE}

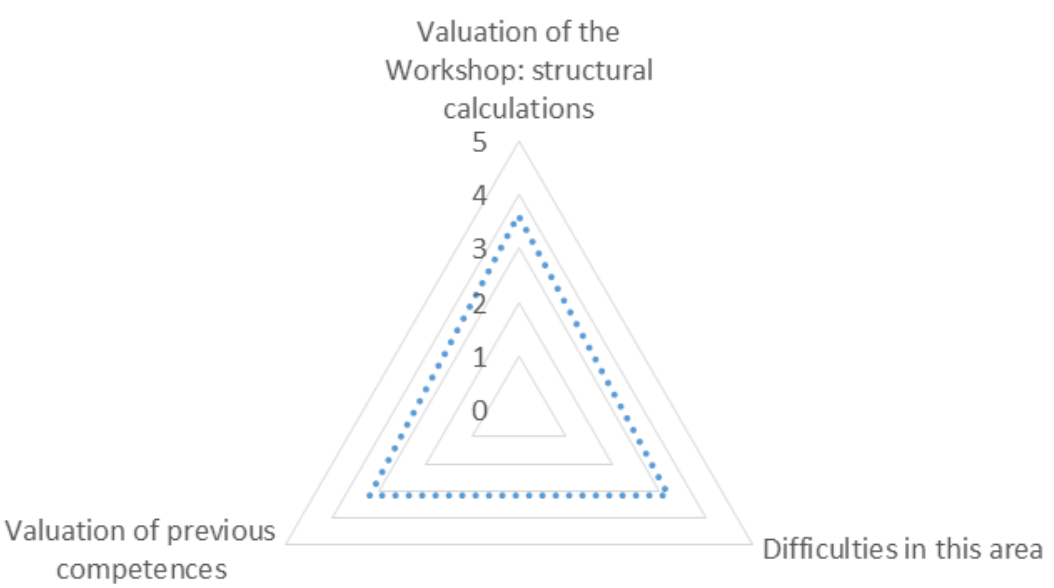

Figure 9. Valuation of the phase 4

PHASE 5. RENDERING OF THE PROPOSAL

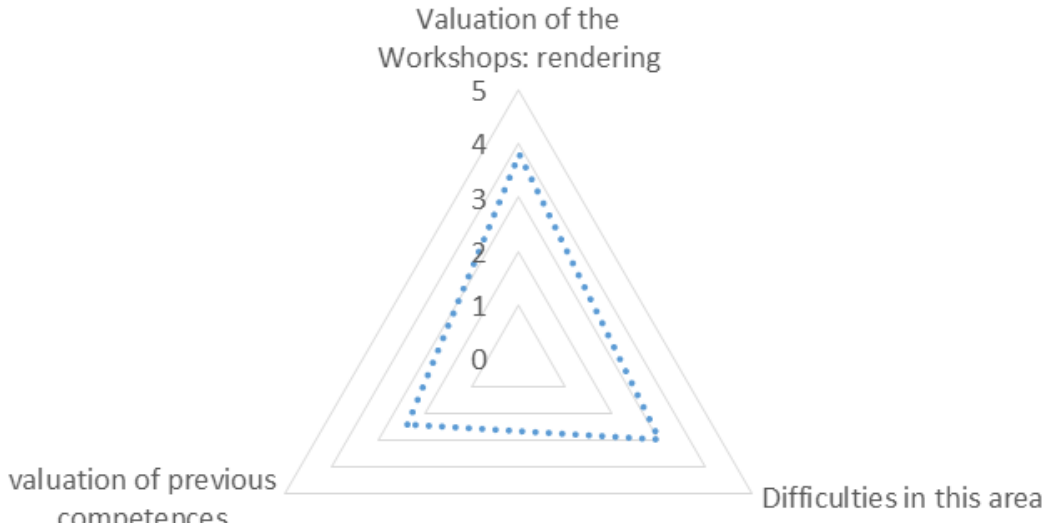

Figure 10. Valuation of the phase 5

\section{CONCLUSIONS}

This project has been positively valued by the students participating in it. Especially, in those aspects related with the experiential learning process and the development of their own creativity. In addition, they considered that the group work at the seminars has been a very enriching environment and has helped them to improve their own learning.

One of the limiting factors that has precluded the achievement of all the objectives of the project has been the technical difficulty related to the inclusion of the footbridges in an augmented reality environment. Training in this matter far exceeds the time available for workshops, which is why a model in augmented reality has not been achieved in all cases. Despite this, the technological workshops have obtained a high evaluation.

Finally, it should be highlighted that all participating students have developed different solutions for the pedestrian bridge (structural and aesthetically), without any enforcement from their advisors. This 
result is very interesting, because it has allowed to establish a dialogue between the students, comparing solutions, construction methods and budgets, in a practice that is very close to the professional one, which has been one of the essential objectives of this project.

\section{ACKNOWLEDGEMENTS}

This work has been developed in the framework of the project "Proyecto de Innovación Educativa IE1617.0400 Concurso de ideas para el diseño y cálculo de una pasarela peatonal en Talamanca de Jarama (Madrid)" supported by the Technical University of Madrid.

The authors are also grateful for the assistance of the Hon. City Council of Talamanca de Jarama (Madrid) as well as the rest of the teachers who have collaborated in this project.

\section{REFERENCES}

[1] A. Benito, B. Cruz, Nuevas claves para la docencia universitaria. Madrid: Narcea. 2005.

[2] A.B. Berrocal, C. López García de Léaniz et al. "Blog PUMA: del aula a la Red," 25 Cuieet, Congreso Universitario de Innovación Educativa en las Enseñanzas Técnicas. Badajoz, 2017.

[3] A. Galán, "Incertidumbres y desafíos de la Universidad Española. Escenarios posibles a corto y medio plazo". Revista de la Asociación de Inspectores de Educación de España, 2013.

[4] F. Adriá, Guías de escuelas creativas. Menú de aprendizaje. $2^{\text {nd }}$ edition, Fundación Telefónica 2017.

[5] M. Stone, La enseñanza para la comprensión, $1^{\text {st }}$ edition, Buenos Aires: Paidós. 1999.

[6] J. Bernabéu, A.B. Berrocal et M.Aguiló, "The construction of "Artifacts", physical handmade devices, as an educational method in civil engineering". INTED2012. pp. 6315-6322 